\title{
Saberes e Práticas do Professor que Ensina Matemática na Formação Continuada
}

\section{Knowledge And Practices of the Teacher Who Teaches Mathematics in Continuing Formation}

\author{
Maria das Graças Bezerra Barretoa; Maria Elisabette Brisola Brito Prado*bcd
}

aUniversidade Metropolitana de Santos. SP, Brasil.

bUniversidade Anhanguera de São Paulo, Programa de Pós-Graduação Stricto Sensu em Educação Matemática. SP, Brasil. 'Universidade Anhanguera de São Paulo, Programa de Pós-Graduação Stricto Sensu em Ensino de Ciencias e Saude. SP, Brasil; ¿Unopar, Programa de Pós-Graduação Stricto Sensu em Metodologia para Ensino de Linguagens e suas Tecnologias. PR, Brasil. *E-mail: bette.prado@gmail.com.

\begin{abstract}
Resumo
Este artigo refere-se a um recorte de pesquisa de doutorado e apresenta reflexões decorrentes da formação continuada de um grupo de professores, com diferentes titulações em Pedagogia e Matemática, sobre como pensam os problemas matemáticos e os veiculam em sala de aula. A trajetória investigativa contou com uma metodologia qualitativa e um papel de intervenção. Os dados coletados foram utilizados para compreender as reflexões dialógicas que dimensionaram o processo de treinamento e para analisar os registros obtidos pelos protocolos de atividades. Os estudos teóricos de Llinares, Shulman, Zeichner, Vergnaud, Ma e Ball Thames e Phelps orientaram a ação formativa e favoreceram a análise reflexiva. As análises demonstraram a importância de reconhecer a competência profissional de cada um e entender como suas atividades formativas se inter-relacionam e se complementam. Conclui-se que a ação formadora explora a diversidade de momentos e promove a constituição de grupos distintos, propicia uma aprendizagem diferenciada e a redefinição das competências profissionais dos professores que ensinam Matemática.
\end{abstract}

Palavras chave: Problemas Aditivos. Projeto Observatório. Estrutura Multiplicativa. Aprendizagem Matemática.

\begin{abstract}
This article refers to an excerpt from doctoral research and presents reflections resulting from the continued formation of a group of teachers, with different degrees in Pedagogy and Mathematics, about how they think about mathematical problems and convey them in the classroom. The investigative trajectory counted on a qualitative methodology and an intervention role. The data collected was used to understand the dialogical reflections that dimensioned the training process and to analyze the records obtained by the activity protocols. The theoretical studies of Llinares, Shulman, Zeichner, Vergnaud, Ma, Ball, Thames and Phelps guided the formative action and favored reflective analysis. The analyzes demonstrated the importance of recognizing each other's professional competence and understanding how their educational activities interrelate and complement each other. It is concluded that the formation-action explores the diversity of moments and promotes the constitution of distinct groups, provides a differentiated learning and the redefinition of the professional competences of teachers who teach Mathematics.
\end{abstract}

Keywords: Additive Problems. Observatory Project. Multiplicative Structure. Mathematical Learning.

\section{Introdução}

As políticas públicas nas últimas décadas têm incentivado a realização de formação continuada de professores propiciando avanços e reflexões nas práticas docentes e a oportunidade de dialogar sobre as dificuldades enfrentadas no cotidiano escolar. Conceberam que o docente para o enfrentamento aos problemas gerados por um mundo globalizado necessitava de conhecimentos curricular, cultural, social e tecnológico, que demandavam atualizações teóricas e metodológicas. Por esse motivo, a formação continuada passou a ser considerado um caminho promissor e propositivo às mudanças esperadas nas práticas docentes e aos diferentes contextos educacionais e regionais de nosso país.

Essa diversidade contextual foi uma das causas responsável por despertar o interesse dos professores por formações continuadas, especialmente, as de matemática.
Situação comprovada nas conversas coletivas ocorridas em formações de professores que ensinam matemática, ao serem questionados sobre suas expectativas e o que esperavam dos encontros da ação formadora. A maioria assegurou esperar conhecer estratégias metodológicas para entender como ensinar de forma diferenciada os blocos de conteúdos da matemática, definidos pelos documentos oficiais, baseados nos Parâmetros Curriculares Nacionais - PCN (Brasil, 1997,1998), que atualmente são definidos como unidades temáticas pela Base Nacional Comum Curricular - BNCC (Brasil, 2018), para o Ensino Fundamental. Alguns esperavam experienciar situações práticas e reais que propiciassem aos seus alunos uma aprendizagem matemática mais compreensiva e significativa. Outros almejavam superar as dificuldades pessoais, com relação a alguns conhecimentos matemáticos, acumuladas na vida estudantil e desconsideradas durante a formação inicial dos cursos de Pedagogia ou de Matemática 
(Barreto, 2016).

As lacunas nos conhecimentos matemáticos dos professores foram fonte de pesquisas realizadas por Barreto (2011, 2016), Moreira (2004), Gregolin (2002), entre outros, assinalando como esses obstáculos foram responsáveis pela inibição de alguns professores diante de atividades e problemas matemáticos propostos que requeriam a seleção de estratégias e procedimentos de solução. As posturas percebidas eram atitudes disfarçadas pelo nervosismo ou pelo olhar de alívio diante do parceiro colaborador ou "resolvedor" dos problemas, que propunham e apresentavam os procedimentos de solução no coletivo. Esses momentos camuflavam a compreensão e os conceitos equivocados desvelados em outras etapas da trajetória formativa.

Essas circunstâncias deram ênfase à importância do atendimento as reais necessidades dos professores participantes das formações e necessidade de aprofundamento nos estudos relacionados à competência profissional do professor que ensina matemática. Também salientaram a importância de ações que despertassem posturas diferenciadas com relação à capacidade de diagnosticar, observar e analisar situações complexas presentes em sala de aula (Serrazina, 2002; Fiorentini, 2009; Nacarato, Grando \& Eloy, 2009; Passos, Oliveira \& Gama, 2009).

Assim, esse artigo apresenta os resultados parciais de uma pesquisa de doutorado e as reflexões propiciadas por uma formação continuada realizada no projeto OBEDUC/CAPES em parceria com uma diretoria estadual de ensino. O propósito foi compreender como os professores pensam problemas matemáticos e os veiculam em sala de aula. Em atendimento ao proposto apresentamos nas seções seguintes: o percurso metodológico, o cenário da formação continuada, a análise dos diálogos e das reflexões realizadas pelos participantes e ações constituintes.

\section{A Teoria Direcionando a Ação Formadora de Matemática}

A trajetória investigativa de natureza qualitativa e de intervenção utilizou como instrumentos para um questionário, protocolo das atividades desenvolvidas pelos participantes e os registros audiovisuais. O questionário assegurou conhecer a história de vida estudantil e profissional das participantes. Os protocolos das atividades permitiram dimensionar os saberes matemáticos, as concepções e as teorias implícitas em suas práticas. Os registros audiovisuais favoreceram analisar as reflexões realizadas durante os momentos de estudo em grupo e do compartilhamento de experiências ocorridos na ação formadora.

Esta pesquisa aprovada pela Comissão de Ética - Parecer Substanciado $n^{\circ} 746.440$ de 11/08/2014 analisou a Formação Continuada de Matemática ocorrida no âmbito do projeto do Programa Observatório da Educação/CAPES, na Universidade Anhanguera de São Paulo, em parceria com duas Diretorias de Ensino do Estado de São Paulo. A formação ocorreu em
11 encontros quinzenais, totalizando 40 horas e envolveu 14 professoras participantes com graduação distinta em Pedagogia e em Matemática, atuantes nas escolas estaduais de Ensino Fundamental. As professoras foram referenciadas por pseudônimos preservando o direito ao sigilo de suas identidades. As professoras de Matemática por PM1, PM2, PM3, PM4, PM5 e as professoras de Pedagogia como: PP1, PP2, PP3, PP4, PP5, PP6, PP7, PP8 e PP9. A pesquisadora desempenhou também o papel de formadora.

A organização de uma formação continuada que envolve um grupo distinto em formação e conhecimento matemático demandou compreender os princípios reflexivos propostos por Zeichner (1993) para fundamentar as situações reflexivas que gerassem diálogo, troca de experiência, colaboração, confiabilidade e participação ativa na busca de soluções para os problemas matemáticos propostos. Esse autor nos alerta para o tipo de reflexão que a formação pretende promover e ressalta a importância de o docente ser incentivado a estudar o seu ensino e a questionar as abordagens dadas aos assuntos propostos. Salienta ainda, a necessidade do incentivo para que as situações propostas sejam testadas na prática.

Por esse motivo, a elaboração dos encontros formativos propiciou vivencias em grupo para que os participantes se sentissem menos solitários e mais confiantes, dispostos a discutir sobre suas práticas. Os professores precisam ser instigados a perceber a importância da interação social, pois ela ajuda a clarificar o que cada um acredita e pratica, ao mesmo tempo em que estimula, dando coragem para enfrentar as etapas ou desafios posteriores (Zeichner, 1993). Essa interação grupal exigiu conhecimentos teóricos que respaldassem a análise e compreensão das diferentes situações de aprendizagem, as pessoais e as encontradas em sala de aula.

A proposta de vivências em grupo e discussões conjuntas entre os participantes encontraram na perspectiva de Llinares (2013) o aporte teórico para o desencadeamento de contextos reflexivos e para a ampliação do conhecimento profissional, de modo a "mirar com sentido" e ensinar matemática. Para o autor essa competência docente está relacionada com a maneira como o professor usa seu conhecimento matemático para analisar os diferentes aspectos que envolvem o seu ensino e a aprendizagem que ele propicia. Os aspectos ressaltados pelo autor estão relacionados ao planejamento e a organização dos tipos de problemas utilizados na realização das tarefas propostas, a gestão da prática envolvendo a interpretação da aprendizagem e a interação com os alunos na construção dos conceitos matemáticos propiciados pelos problemas propostos. Finalmente, para analisar a prática do professor é preciso conhecer como constrói seu conhecimento e o seu discurso argumentativo matemático e qual a atenção dada à reflexão sobre a ação.

Essas competências esperadas do professor direcionaram para uma formação que supere o enfoque no conhecimento do conteúdo matemático e promova o interesse por outros 
conhecimentos e seus aspectos. Para isso, precisaria propiciar o rompimento com a dicotomia entre teoria e prática relacionadas ao ensino de matemática e gerar a necessidade de conhecimentos fundamentais e indispensáveis para uma prática mais consciente e competente. Segundo os estudos de Shulman (1986) ampliados por Ball, Thames e Phelps (2008), a competência profissional docente envolve o conhecimento do conteúdo, o conhecimento do currículo e o conhecimento pedagógico do conteúdo.

Ball et al. (2008) compreenderam que o conhecimento do conteúdo matemático e o conhecimento pedagógico do conteúdo, o como ensinar, favoreciam a percepção de como as orientações dadas aos professores influenciavam as formas de abordagem dos conteúdos em sala de aula. Entenderam que o ensinar envolvia mais do que respostas certas ou erradas, ele exigia conhecimentos que extrapolassem o assunto trabalhado com os alunos. O ensino requeria antecipação dos pensamentos dos alunos com relação às facilidades, dificuldades e confusões conceituais, para no momento da intervenção saber como analisar a fonte dos erros matemáticos e poder colaborar para que haja avanços. Os autores reconheceram que esse processo complexo demandava ampliação do saber matemático dos professores, saber mais matemática e suas relações (conhecimento do currículo), como também, conhecer as diferentes matemáticas (conhecimento pedagógico do conteúdo).

Os estudos de Ma (2009) envolvendo professores americanos e chineses constatou que o desconhecimento dos professores dos saberes e não saberes de seus alunos influenciava na escolha de caminhos colaboradores que propiciassem a aprendizagem dos alunos. Observa-se que os professores empenhados em estudos intensivos, no individual ou no coletivo, dos materiais de ensino oficiais utilizados no cotidiano escolar, ampliavam seu conhecimento da matemática elementar e sentiam-se mais seguros para ensinar com mais clareza a matemática. Ma assegura ainda, que professores abertos a entender os procedimentos de soluções apresentados pelos alunos vencem sem receios e admitem que podem aprender matemática com eles, pois consideram os alunos como "fazedores" de matemática e capazes de apresentar soluções inesperadas.

Para vencer os receios, as inibições, as dúvidas e a insegurança matemáticas dos professores e colaborar com o entendimento das soluções próprias e das apresentadas pelos dos alunos, buscamos embasamento nos estudos teóricos de Vergnaud (2009) a respeito da diversidade de tipos de problemas com estruturas aditivas e multiplicativas e dos pensamentos operativos que os envolvem. Vergnaud (2010) assegura que a constituição do conhecimento matemático ocorre no contato com uma variedade de situações e conceitos. A compreensão de uma situação por mais simples que seja envolve mais de um conceito e um único conceito necessita de situações diversificadas.

Por isso, o professor precisa conhecer as relações propostas para os diferentes tipos de problemas e entender as dificuldades encontradas pelos alunos na escolha de soluções para os problemas que envolvem as operações de adição, subtração, multiplicação e divisão. Precisam compreender que a escolha das situações e dos problemas diversificados definirá o desenvolvimento dos procedimentos de solução dos alunos e a estrutura de seu conhecimento matemático.

Em Nunes e Bryant (1997), encontramos uma análise de como os alunos pensam problemas matemáticos e a evidência da importância do desenvolvimento do raciocínio matemático para a vida cotidiana. Para eles, as situações que favorecem o raciocínio multiplicativo são diferentes das aditivas, uma vez que não envolve ações de unir e separar. Consideram a multiplicação mais difícil que a adição.

Para Nunes e Bryant (1997), a divisão sempre foi uma dificuldade a ser superada ao longo dos tempos. Os métodos aprendidos na escola passaram por alguns processos evolutivos. Antes, a divisão e a multiplicação envolviam maneiras extremamente detalhistas e centradas em muita prática. Atualmente, apesar de lidarmos com algoritmos variados, encaminhando aos mais econômicos, permitindo a realização com rapidez e precisão, as dificuldades ainda persistem, mesmo para muitos alunos que tenham amplo conhecimento de número. Muitos professores ainda insistem em ensinar os jeitos de resolver problemas ou algoritmos, limitando a descoberta dos alunos, que poderiam ter a oportunidade de aprender melhor com a constatação das relações, o estabelecimento de hipóteses e a verificação destas na busca por uma solução.

\section{Ação Formadora um Cenário Dialógico de Trocas e Aprendizagens}

Fizemos uma formação continuada envolvendo 14 professoras participantes com graduação distinta em Pedagogia e em Matemática. Objetivamos que elas cumprissem seu papel reflexivo e mediador de práticas. Para tanto, realizamos, no primeiro encontro um levantamento das reais necessidades matemáticas e das expectativas das professoras perguntando: "Quais expectativas você tem com relação a essa Formação de Matemática?".

As discussões foram realizadas em duplas e relatadas no coletivo. Algumas das colocações despertaram o nosso interesse investigativo. As professoras PP1 e PP5 esperavam "adquirir habilidades necessárias para a aplicação do conteúdo matemático". A professora PP2 declarou enfática: "Que a formação me faça gostar de Matemática". E as professoras PP3 e PP7 almejavam: "ampliar a visão sobre o aluno e facilitar a prática docente". Sabíamos das dificuldades das professoras pedagogas, mas o que mais nos surpreendeu foram as declarações das professoras de matemática PM2 e PM5 de que almejavam, "experiências novas para serem aplicadas em sala" e da professora PM4, cujo desejo era "aprofundamento sobre o tema".

Para atender as diferentes expectativas, planejamos para 
o próximo encontro como fio condutor, duas situações de caráter diagnóstico para ampliar nosso entendimento sobre o saber dessas professoras. Na primeira situação diagnóstica foi realizada a atividade de formulação de problemas com estruturas multiplicativas (multiplicação e divisão); na outra, uma atividade de classificação da lista contendo problemas com estruturas aditivas e multiplicativas.

A atividade de formulação de problemas realizada pelas participantes nos revelou quais tipos de problemas eram oferecidos com mais constância em sala de aula. O resultado das propostas elaboradas em duplas foi uma coletânea contendo 57 problemas que utilizavam em suas soluções as operações de multiplicação e/ou divisão. A elaboração foi realizada sem material de apoio e mesmo assim, apresentou um número significativo de problemas baseados nos modelos encontrados nos livros didáticos e utilizados no cotidiano escolar.

A coletânea com os 57 problemas demandou a necessidade de uma análise classificatória realizada pelos grupos. As professoras constataram que 48 desses problemas exploravam a ideia de proporcionalidade simples, os 9 restantes, relacionavam-se as noções de comparação, combinatória e configuração retangular (produto de medida). O grupo ao ser questionado com relação à diferença entre os tipos de problemas oferecidos em sala de aula, respondeu conforme declaração da professora PP2, que refletiu o pensar uníssono do coletivo: "Eles são muito difíceis de serem ensinados".

A explicação recebida precisou de maiores esclarecimento. Sabíamos que os problemas com ideia de configuração retangular eram mais utilizados pelas professoras pedagogas e provocamos uma discussão no coletivo. Os argumentos foram díspares. A professora PM1 explicou: "utilizo esse tipo de problema quando vou tratar dos assuntos área e perímetro". Ao mesmo tempo, a professora PP4 afirmou: "sempre ofereço esse tipo de problema para mostrar a multiplicação como soma de parcelas iguais".

A quantidade de problemas envolvendo a ideia de proporcionalidade comprovava a frequência com que eles adentravam a sala de aula e a explicação expressa pela maioria dos grupos associava-se à oferta dos livros didáticos. Novamente o depoimento professora PM5 acabou concentrando a opinião silenciosa de muitos da sala: "Eles são mais simples de resolver".

Essas discussões com relação à classificação dos problemas sustentaram o desenrolar dos próximos encontros; cada tipo de problema foi abordado individualmente. As atividades, elaboradas pela formadora, eram vivenciadas em grupo e atendiam as seguintes etapas: análise e resolução, prognóstico e elaboração de um plano de ensino para um dos problemas recebido e aplicação dos problemas selecionados em sala de aula. No decorrer dos encontros notamos que as professoras foram reconhecendo as dificuldades evidenciadas por seus alunos para resolver problemas, pois, no início, aparentavam pouca reflexão sobre o assunto.
O planejamento dos encontros baseou-se em Nunes e Bryant (1997) e Vergnaud (2009). Esses autores destacam que conhecer uma diversidade de problemas permiti a apropriação de diferentes estratégias e facilita a tomada de decisão refletindo nas escolhas futuras dos alunos. Os alunos, de posse da diversidade, passam a utilizar em suas soluções, procedimentos mais rápidos e econômicos de cálculo.

Observamos que as professoras esperavam de seus alunos procedimentos de cálculos convencionais, pois acreditavam serem estes os únicos que induzem ao acerto. Os argumentos das professoras evidenciando as dificuldades dos alunos em resolver problemas apoiaram-se em dois aspectos: a dificuldade na leitura e a inabilidade de realizar o cálculo convencional. Esses aspectos pareciam estar muito mais relacionados ao enfrentamento das professoras com suas próprias dúvidas e incertezas para resolver e ensinar problemas matemáticos. Para colaborar na superação das dificuldades e ampliar a competência profissional do professor, nos reportamos às observações de Llinares (2013); para o autor, o professor, para "mirar com sentido" e ensinar Matemática, precisa vivenciar situações de interação com as atividades dos alunos para compreender os procedimentos de solução apresentados.

A aplicação dos problemas selecionados em sala de aula ganhou um espaço no período inicial de cada encontro. Os grupos formados por professoras de Pedagogia e da Matemática realizaram as análises das atividades dos alunos mediadas por uma ampla discussão que suscitou a compreensão dos cálculos encontrados e instigou o reconhecimento daqueles que poderiam ser explorados em sala de aula.

Cabe ressaltar que, entre a formulação dos problemas e sua classificação, realizamos a segunda ação de caráter diagnóstico, a atividade de classificação de uma lista de problemas com estruturas aditivas e multiplicativas. Nosso intuito era que o conhecimento das professoras fosse revelado. Essa atividade realizada em agrupamentos mistos propiciou conhecer os saberes das professoras e oportunizou trocas de experiências entre as participantes. As professoras pedagogas auxiliaram as de matemática na realização da tarefa, especialmente com relação às terminologias utilizadas. Muitos questionamentos surgiram e esclarecimentos exigidos a respeito dos problemas aditivos, permitindo sanar as dúvidas com relação às diferenças entre os significados envolvendo a composição e a transformação (positiva e negativa), conforme explicitado por Vergnaud (2010). As professoras pedagogas solicitaram uma retomada teórica sendo apoiadas pelas professoras de matemática que desconheciam alguns tipos de problemas. Ampliamos os estudos com a teoria dos campos conceituais de Vergnaud $(2009,2010)$ acerca dos diferentes tipos de problemas aditivos e discutimos como alguns deles, por sua complexidade, resultavam em erros e incompreensões na escolha das estratégias de solução dos alunos.

A última atividade da pauta desse encontro apresentava como proposta a seleção e a adaptação de alguns problemas aditivos da lista para serem aplicados em sala de aula, sendo 
realizada por grupos formados por ano de atuação das participantes. Quatro problemas foram selecionados para serem realizados pelos alunos, individualmente ou em duplas. Cada grupo registrou o prognóstico do desempenho de seus alunos.

\section{Análise das Atividades dos Alunos}

A etapa da pauta destinada à análise das atividades realizadas pelos alunos possibilitou observarmos como as professoras pensavam didaticamente o conteúdo matemático e compreendiam os procedimentos de solução utilizados pelos alunos. Algumas professoras mostraram-se surpresas com os algoritmos pessoais apresentados pelos alunos dos anos finais. Situação que deixou as professoras de Matemática bastante desconcertadas, pois em seus prognósticos garantiram seus alunos realizariam a tarefa com facilidade utilizando inclusive, o cálculo convencional. No entanto, certas estratégias de soluções elaboradas pelos alunos dos anos finais do Ensino Fundamental eram semelhantes às apresentadas pelos alunos iniciantes. Os erros percebidos que representavam as dificuldades enfrentadas para interpretar e resolver os problemas foram dimensionados e passaram a ter outro sentido e significado para as professoras.

A análise em grupos dos procedimentos de solução pautou-se em considerar o que os alunos sabem e pensam sobre problemas aditivos. Encerramos o momento analítico no coletivo viabilizando a validação das observações realizadas, um diálogo sobre a trajetória do pensamento dos alunos e a troca sobre as diferentes abordagens dos algoritmos envolvendo a adição e a subtração. Entendemos que algumas professoras de Matemática que haviam assinalado em vermelho o procedimento diferente do esperado, retomaram a correção e assinalaram os saberes matemáticos de seus alunos.

Para exemplificar esse processo dinâmico do ensinar e aprender foram selecionados procedimentos de soluções apresentados por alunos do $6^{\circ}$ Ano e do $8^{\circ}$ Ano, para o mesmo problema aditivo com a ideia de transformação.

A seguir, podemos observar o procedimento do aluno A do $6^{\circ}$ Ano, na Figura 1:

Figura 1 - Procedimento de solução do aluno A

1) Lucas tinha 187 figurinhas e quando seu irmäo the deu algumas figurinhas, ficou com 235 figurinhas. Quantas figurinhas ele ganhou de seu irmão?

$$
\frac{187}{\frac{235}{48}}
$$

Fonte: As autoras.

$\mathrm{O}$ algoritmo do aluno A reflete uma leitura literal baseada em modelo de problemas anteriores e centrada na palavrachave dar/ganhar (ideia de acrescentar), o que induz o aluno a desconsiderar o contexto (algumas figurinhas). O esquema organizador dos dados do problema refere-se à operação de adição, mas o procedimento que o soluciona é a operação de subtração. As professoras PP5 e PM3 perceberam que o aluno A utilizou a operação adição, mas não compreendiam a escrita do algoritmo. Consideraram a possibilidade de o resultado ter sido fruto do cálculo mental encontrando a diferença (ideia de comparar) entre as quantidades de figurinhas. No entanto, a escrita do cálculo convencional demonstrou a preocupação com a estrutura do algoritmo e o compromisso com seu pensar, a certeza do resultado correto.

Alguns alunos da turma apresentaram o algoritmo da adição como procedimento de solução para a mesma atividade a partir de uma escrita diferente da apresentada pelo aluno A, sendo: $187+\underline{48}=235$. Outros demonstraram o uso sem questionamento do algoritmo convencional, e realizaram o seguinte procedimento: $187+235=422$.

A solução do aluno B, do $8^{\circ}$ Ano, pode ser observada na figura 2, a seguir:

Figura 2 - Procedimento de solução do aluno B

1) Lucas tinha 187 figurinhas e quando seu irmão Ihe deu algumas figurinhas, ficou com 235 figurinhas. Quantas figurinhas ele ganhou de seu irmão?

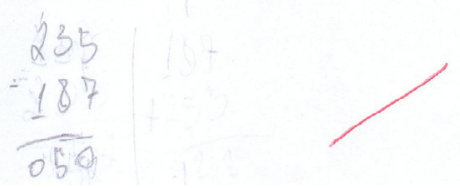

Fonte: Os autores.

O aluno B apresentou compreensão e interpretação do problema demonstrada pela escolha do procedimento de solução. Entretanto ao resolver o cálculo convencional da subtração, o resultado encontrado pelo aluno demonstra a limitação de seu conhecimento com relação à regra que o rege. A subtração exige conhecimento de abordagens diferenciadas como a compreensão da decomposição do número 235 (100 + $120+15)$. As professoras PM1 e PM4 entenderam que o aluno operou apenas com a ideia de retirar $(130-80=50)$ e $(100-$ $100=0$ ), observaram que ele desconsiderou totalmente a casa das unidades e afirmaram que o resultado errado demonstrava a incompreensão do aluno. As professoras PP6 e PP9 colaboraram no esclarecimento da situação: o aluno se apoiou em afirmação ouvida por várias de nós em anos anteriores, “na subtração não é possível tirar um número maior de um número menor". As participantes entenderam que algumas afirmações, realizadas com a intenção de esclarecimento, desconsideravam a compreensão das características do sistema de numeração decimal (composição e decomposição) e permitiam a transposição do preceito para outros campos numéricos gerando erros.

Outro procedimento diferenciado na solução apresentada pelo aluno do $8^{\circ}$ Ano, podemos observar na Figura 3. 
Figura 3 - Procedimento de solução do aluno C

1) Lucas tinha 187 figurinhas e quando seu irmão Ihe deu algumas figurinhas, ficou com 235 figurinhas. Quantas figurinhas ele ganhou de seu irmão? y

$$
\begin{array}{r}
235 \\
-49 \\
\hline 187
\end{array}
$$

Fonte: Dados da pesquisa.

Essa forma de apresentar o procedimento de cálculo esteve presente também na solução de outros alunos da mesma turma, assim como em outros anos, causando espanto nas professoras de matemática. Esses alunos que para elas eram "resolvedores" de equações simples, segundo PM3 "esse tipo de fazer a conta estava fora de questão". Encontrar uma justificativa para um procedimento de cálculo diferente do convencional foi muito difícil para as professoras de Matemática. Elas nunca haviam se debruçado para analisar o registro matemático de seus alunos, a correção considerava somente o resultado. As professoras PP4 e PP7 mostraram as atividades de seus alunos com algoritmos semelhantes, realizaram a análise do que o aluno já sabia e declararam que esse aluno precisava de ajuda para compreender a relação entre as escritas dos cálculos mental e convencional da subtração.

As soluções inesperadas desencadearam diálogos reflexivos e compartilhamento de experiências sobre a provisoriedade dos conhecimentos matemáticos e o desenvolvimento gradativo dos diferentes tipos de cálculo. Observamos que os comentários realizados inicialmente precisavam de olhares mais atentos para superar um simples conferir de resultados, separando os cálculos certos dos errados. A observação mais detalhista das atividades dos alunos necessitou de intervenção formadora, pois os diálogos nos grupos evidenciaram as dificuldades das professoras em entender os procedimentos apresentados e oportunidade de aprender na interação com o outro. O pouco conhecimento de procedimentos diferenciados de cálculo dificultou a compreensão e a elaboração de encaminhamentos mais sistematizados. A intervenção formadora favoreceu a percepção da importância da construção de repertório de cálculo diversificado, das professoras e de seus alunos, promovendo maior agilidade em resolver problemas e ampliação do conhecimento pedagógico matemático.

Esse momento formador de análise encontra respaldo em Ball et al. (2008) e Ma (2009), ao assegurarem ser tarefa do professor munir-se de uma competência matemática ampla, transitando pelas diferentes relações matemáticas, de modo que garanta explicações e fundamentações lógicas para os procedimentos apresentados pelos alunos. O professor ao entender os diferentes procedimentos poderá transformá-los em linguagem matemática, mostrando que os jeitos de pensar dos alunos tem lógica e explicação matemática.

Os diálogos ocorridos e as apresentações coletivas favoreceram momentos de troca de experiências e reflexão, possibilitando repensar e compartilhar caminhos: cooperadores para a compreensão dos diferentes tipos de cálculos e favoráveis a ampliação de aprendizagens. Aprendizado propiciado pela oportunidade de ouvir e de falar para o outro, de defender suas ideias e saberes e de transformar seus fazeres (Barreto e Prado, 2018).

Nessas discussões outro assunto foi abordado, os materiais didáticos utilizados em suas práticas. Segundo Ma (2009), o estudo dos materiais didáticos em cooperação com os colegas incentiva a elaboração de abordagens que permitam um maior entendimento dos conteúdos matemáticos. Ao término do encontro, após o fechamento teórico, a quantidade de informação causou admiração as participantes. Houve também comentários a respeito do pouco tempo para o processamento do conteúdo matemático. O conhecimento havia provocado grandes desequilíbrios e precisou ser entendido e acomodado. As professoras reconheceram que a oferta de problemas matemáticos com diferentes significados: precisa estar mais presente nas práticas e exige dos alunos uma diversidade de conhecimentos em suas soluções. Afinal só se aprende a resolver problema, resolvendo.

Os tipos de problemas aditivos foram tratados em um único encontro, em atendimento a real necessidade de conhecimento das professoras. Os demais encontros mantiveram o foco de nosso estudo, os problemas com estrutura multiplicativa. As análises reflexivas, os diálogos, as apresentações no coletivo e as trocas de experiências constituíram a trajetória formadora dos demais encontros.

\section{Conclusão}

No intuito de buscar compreender como os professores pensam problemas matemáticos e os veiculam em sala de aula, este estudo constatou que as professoras pedagogas e as de matemática perceberam a necessidade de saber os conteúdos matemáticos e suas relações, como também as estratégias metodológicas utilizadas para ensiná-los. Compreenderam a responsabilidade com cada etapa do Ensino Fundamental que exige um aprofundamento e a consolidação do conhecimento dos alunos, preparando-os para lidar com ideias matemáticas mais complexas e ampliar seu repertório para resolver problemas matemáticos e observados na vida.

Os diferentes momentos na formação evidenciaram a importância de as atividades serem vivenciadas grupalmente e fomentaram a análise, a reflexão e os diálogos, favorecendo assim, o aflorar dos saberes dos professores. Eles permitiram também, sinalizar os tipos de atividades presentes nas salas de aula e as que necessitavam ser valorizadas nas aulas de matemática, no Ensino Fundamental.

Esse processo reflexivo e coletivo permitiu observar como a formação com professores atuantes em diferentes segmentos do Ensino Fundamental, com formações diferenciadas, precisavam ouvir soluções e opiniões a respeito de como ensinar matemática, uns dos outros. Essa vivência diferenciada garantiu o reconhecimento de como suas ações se complementam e se inter-relacionam e a valorização da competência profissional de cada um. Constatou-se que 
a metodologia explorada pela ação formadora assegurou uma relação de credibilidade e confiabilidade, propiciando uma participação mais ativa das professoras, aprendizados diversificados e o compartilhamento de saberes e práticas sobre problemas matemáticos.

Concluímos que a ação formadora ao explorar uma diversidade de momentos, valoriza o trabalho em grupo e que a constituição de grupo distinto, propicia um processo de aprendizagem e de ensino matemático mais efetivo e a ressignificação das competências profissionais de professoras que ensinam Matemática. No entanto, algumas situações merecem atenção investigativa como o modelo de uma ação formadora que influencia a ressignificação de prática de professores que ensinam matemática e as mudanças ocorridas no processo de aprendizagem dos alunos, no período posterior a formação continuada do professor.

\section{Referências}

Ball, D.L., Thames, M. H., Phelps, G. (2008). Content Knowledge for Teaching: What Makes it Special?. J. Teacher Educ., 59, 389-407. doi: http://dx.doi.org/10.1177/0022487108324554.

Barreto, M.G.B. (2011). A formação continuada de matemática dos professores dos anos iniciais o ensino fundamental e seu impacto na prática de sala de aula. Dissertação (Mestrado em Educação Matemática), Universidade Bandeirante de São Paulo, São Paulo.

Barreto, M.G.B. (2016). Formação continuada: um desvelar de saberes dos professores da educação básica em diálogos reflexivos sobre a estrutura multiplicativa. Tese (Doutorado em Educação Matemática). Universidade Anhanguera de São Paulo, São Paulo.

Barreto, M.G.B., Prado. M.E.B.B. (2018). Um design do processo formativo: vivências, teorias e saberes do professor que ensina matemática. Jornal Internacional de Estudos em Educação Matemática, 11, 245-252. doi: https://doi.org/10.17921/21765634.2018v11n3p245-252.

Brasil. (1997). Secretaria de Educação Fundamental. Parâmetros curriculares nacionais: Matemática. Brasília: MEC/SEF.

Brasil. (1998). Secretaria de Educação Fundamental. Parâmetros curriculares nacionais: Matemática / Secretaria de Educação Fundamental. Brasília: MEC

Brasil. (2018). Base Nacional Curricular Comum (BNCC). Brasília: MEC.

Fiorentini, D. (2009). Quando acadêmicos da universidade e professores da escola básica constituem uma comunidade de prática reflexiva e investigativa. In: D. Fiorentini, RC,
Grando, \& R.G. Miskulin. Práticas de formação e de pesquisa de professores que ensinam matemática. (pp. 233-255). Campinas: Mercado das Letras.

Gregolin, V.R. (2002). O conhecimento Matemático Escolar: Operações com números naturais (e adjacências) no Ensino Fundamental. ese (Doutorado em Educação). Universidade Federal de São Carlos, São Carlos.

Llinares, S. (2013). O desenvolvimento da competência docente de "olhar profissionalmente" o ensino-aprendizagem das matemáticas. Educar em Revista, 50, 117-33. doi: https://doi. org/10.1590/S0104-40602013000400009.

Ma, L. (2009). Saber e Ensinar Matemática Elementar. Lisboa: Gradiva.

Moreira, P. C. (2004). O conhecimento matemático do professor: formação na licenciatura e prática docente na escola básica. Tese (Doutorado em Educação). Faculdade de Educação da Universidade Federal de Minas Gerais, Belo Horizonte.

Nacarato, A.M., Grando, R.C. \& Eloy, T.A. (2009). Processos formativos: compartilhando aprendizagens em Geometria com diferentes mídias. In: D. Fiorentini, R.C. Grando, \& R.G., Miskuli. Práticas de formação e de pesquisa de professores que ensinam matemática. (pp. 189-210). Campinas: Mercado das Letras.

Nunes, T., Bryant, P. (1997). Crianças fazendo matemática. Porto Alegre: Artes Médicas.

Passos, C.L.B., Oliveira, R.M.M.A. \& Gama, R.P. (2009). Práticas potencializadoras do desenvolvimento profissional docente: atividade de ensino, pesquisa e extensão. In: D. Fiorentini, R.C. Grando, \& R.G., Miskuli. Práticas de formação e de pesquisa de professores que ensinam matemática. (pp.147168). Campinas: Mercado das Letras.

Serrazina, L. (2002). A formação para o ensino da Matemática na Educação Pré-escolar e no $1^{\circ}$ ciclo do Ensino Básico. Portugal: Porto Editora.

Shulman, L.S. (1986). Those who understand: knowledge growth in teaching. Education Researcher, 15, 4-14. doi: https://doi. org/10.1177\%2F002205741319300302 .

Vergnaud, G. (2009). A criança, a matemática e a realidade: problemas do ensino da matemática na escola elementar. Curitiba: UFPR.

Vergnaud, G. (2010). Teoria dos Campos Conceituais. In: T.M.M. Campos. Curso Monográfico Altos Estudos. São Paulo: UNIBAN.

Zeichner, K.N. (1993). A Formação Reflexiva de Professores: ideias e práticas. Lisboa: Educa. 